\title{
Um estudo sobre clientes indesejados em empresas de pequeno porte
}

\author{
Favio Akiyoshi Toda*
}

\begin{abstract}
Resumo
Clientes Indesejados fazem parte da rotina de muitas empresas e, infelizmente, afetam não apenas os processos existentes das firmas, mas prejudicam também a motivação dos funcionários e, por vezes, geram incômodos em outros clientes. Este estudo exploratório investigou os tipos de clientes indesejados em negócios de pequeno porte, em academias de ginástica, bares, pet shops e salões de beleza, junto aos funcionários de atendimento e de venda que estavam na "linha de frente" com os clientes. A compreensão desta realidade contribui para repensar algumas ações que venham a proporcionar maior satisfação dos funcionários, buscando treiná-los para lidar com tais dificuldades.
\end{abstract}

Palavras-chave: Clientes indesejados. Demarketing. Pequenas Empresas.

* Doutor em Administração pela PUC-Rio. Professor do Departamento de Empreendedorismo e Gestão da Universidade Federal Fluminense (STE/ UFF) e do Mestrado Profissional em Gestão e Estratégia da Universidade Federal Rural do Rio de Janeiro (MPGE/ UFRRJ). E-mail: faviotoda@id.uff.br 


\section{Introdução}

Quando se estuda o que é marketing pela primeira vez, é comum que os estudantes venham a ouvir a expressão "o cliente sempre tem razão", um clichê que vira para algumas empresas um lema a seguir em seu relacionamento com os clientes. Exemplo mais significativo disso é a regra n. 1, elaborada por Sam Walton, fundador do Walmart, que diz que o cliente sempre tem razão; e a regra n. 2 coloca que, na eventualidade do cliente estar errado, volte para a primeira regra.

Entretanto, a realidade observada no mercado brasileiro é diferente, tanto pelas empresas, em que algumas delas não estão comprometidas em atender as necessidades dos clientes com respeito, visto as inúmeras reclamações apresentadas nos noticiários jornalísticos; quanto pela cultura da malandragem, que é retratada como algo de valor e de destaque na sociedade, constituindo-se, inclusive, como parte da identidade nacional (DAMATTA, 1997), notada, por exemplo, na obra de Jorge Amado Capitães de Areia. Tais características da sociedade acabam por permear a relação de negócios entre empresas e clientes.

Inicialmente o demarketing foi tratado apenas como uma questão econômica para produzir ajustamento da demanda e da oferta. Kotler e Levy introduziram, em 1971, esse conceito importante para que as empresas se preocupassem em ajustar a demanda com os objetivos de longo prazo, em vez de desenvolver ações de forma míope na busca do incremento de vendas. Em situações que ocorre o excesso de demanda ou na existência de uma demanda indesejada - por exemplo, de hóspedes que não possuem o perfil do público frequentador de um determinado hotel -, o demarketing seria uma parte do trabalho de marketing com a responsabilidade de desencorajar compras dos consumidores de um modo geral ou segmentado, momentaneamente ou de forma definitiva. $\mathrm{O}$ foco das empresas de captar novos clientes de forma incessante e desmedida pode ofuscar a atividade de gestão de marketing e ter como consequência um nível de insatisfação dos clientes existentes, contribuindo na destruição da imagem da empresa (KOTLER; LEVY, 1971).

Gristein e Nisan (2009) mencionam que os estudos em demarketing, no âmbito acadêmico, estão focados principalmente no consumo de cigarros, no uso de drogas, na conservação de energia, enfim, em temas mais relacionados à política e à saúde pública, e não a ambientes de negócios privados. Sullivan (2008) também apresenta o uso do demarketing para desestimular o consumo de álcool e papel. Com a ampliação da discussão sobre a importância de se desenvolver uma consciência da preservação do meio ambiente e de ações que estejam ligadas ao movimento 
socialmente aceitável, assuntos ligados ao desencorajamento de compras têm sido também observados com frequência na literatura acadêmica.

Em Gautier (2001), percebe-se que o demarketing, nos dias de hoje, também é resignificado como a gestão do cliente indesejado. Nesta direção, Gordon (2006) alerta para a existência de clientes problemáticos e outros não rentáveis, e apoia a ideia de que esses devem ser colocados para fora da empresa, enquanto ela deve focar forças e recursos em vínculos com clientes realmente válidos. Gautier (2001) comenta que, após a British Airways divulgar publicamente a efetividade de suas ações em demarketing, motivou outras empresas a também relatarem publicamente suas ações.

Medway e Warnaby (2008), ao abordarem a problemática oriunda da concorrência entre cidades, países e lugares na disputa por turistas e instalações de empresas, apresentam exemplos de estratégias, destacando ações de demarketing como parte de um conjunto integrado de ações para trabalhar o Marketing de Lugares, afastando turistas indesejáveis. Os autores apontam que alguns locais turísticos não desejam receber determinadas pessoas com comportamentos indesejáveis, que causam perturbações na localidade e que podem descaracterizar o modo como é vista daquela região entre os turistas.

Assim, o presente artigo espera contribuir para a literatura com um trabalho sobre clientes indesejados, especificamente dentro de pequenas empresas, tema que aparece na literatura acadêmica relacionado ao demarketing. Esse estudo desenvolve recomendações aos gestores de negócios sobre clientes indesejados, e sua relevância está no fato de atuar na motivação dos funcionários frente aos problemas causados por esse tipo de clientes, pois a ocorrência de situações problemáticas pode afetar seriamente a qualidade dos serviços prestados aos demais clientes. Contribui também para as empresas repensarem suas estratégias mercadológicas com clientes indesejáveis, pois estão sujeitas a recebê-los em seus estabelecimentos.

\section{Referencial teórico}

Apesar de o demarketing parecer um assunto de fácil entendimento e representar-se apenas como um marketing invertido para muitos, Kotler e Levy (1971) apontam que existem questões que deveriam ser examinadas pelas consequências que uma gestão malfeita pode ocasionar para a marca de uma empresa. Colocam também que o nível ótimo de realização de estratégias em decisões sobre Produto, Preço, Praça e Promoção (os 4 Ps) não é tão fácil de determinar, e o erro pode ser muito prejudicial, gerando queda nas vendas acima do previsto e causando 
problemas irreparáveis a longo prazo. Sullivan (2008) apresenta outra questão sobre o medo dos executivos em realizar uma atividade de demarketing com seus clientes, pois é uma decisão difícil de ser tomada, principalmente quando investimentos em marketing forem altos.

Kotler e Levy (1971) descrevem três formas para realizar o demarketing e um quarto tipo não intencional por parte da empresa. São eles: (1) demarketing geral - quando o objetivo da empresa é reduzir o nível total da demanda, pode acontecer pelo fato de uma instituição dispor de uma produção insuficiente para atender a demanda ou o aumento dela; (2) demarketing seletivo - quando o objetivo é reduzir apenas em certa classe de clientes ou em um segmento de mercado, restringindo sua demanda para determinados segmentos não rentáveis ou que possam atrapalhar os segmentos servidos pela empresa; e o (3) demarketing aparente - quando a instituição passa a impressão ao público de estar querendo uma redução de venda, porém a intenção, contrariamente, é ampliar a demanda, por exemplo, através de um ponto de venda desorganizado: desse modo uma empresa que poderia afugentar os clientes, passa a ilusão de que os preços estão mais baixos do que os praticados, assim acaba aproximando-os com a ideia de que encontrarão excelentes preços.

As seguintes estratégias poderiam ser adotadas pelas empresas para a redução da demanda, de acordo com Kotler e Levy (1971): reduzir investimentos publicitários e modificar o conteúdo das mensagens; reduzir promoções nos pontos de vendas; reorientar os clientes para outros produtos da empresa; aumentar o preço e as condições de vendas, propiciando o aumento dos custos para o cliente na transação do negócio; reduzir a qualidade do produto ou do conteúdo; e reduzir a sua distribuição.

Por outra ótica, Gautier (2001) destaca a importância de avaliar adequadamente uma política em demarketing por parte da empresa, esta precisa considerar três pontos essenciais: o valor do cliente ao longo do tempo, a sua contribuição nos custos fixos que a empresa possui e a importância dele dentro da carteira de clientes. Para Gautier (2001), os clientes indesejados podem ser trabalhados pelas empresas das seguintes formas: (a) identificar os clientes indesejados, convidando-os para renegociar seus contratos e aqueles que não o quiserem serão considerados indesejados; (b) realizar ações em demarketing quando a economia estiver em situação favorável; (c) apontar os níveis mínimos de transações/compras desejadas para que clientes indesejados sintam-se "amedrontados"; (d) não incluir os clientes indesejados em promoções da empresa em uma abordagem mais indireta; (e) providenciar um fornecedor alternativo para o cliente; (f) apresentar, através de imagem e publicidade, o tipo de cliente desejado pela empresa, para que o próprio 
cliente manifeste vontade de retirar-se; (g) ou, então, apenas dizer que a empresa não pode permitir a continuidade da relação entre as partes com qualquer grau de sensibilidade.

Exemplos de demarketing podem ser observados na prática. Por exemplo, Macstravisc (2008) apresenta um conjunto de ações que um hospital pode empregar quando enfrenta problemas no setor de emergência, pois manter pacientes não urgentes nele gera problemas de atendimento e confusões, além de sobrecarregar a equipe do hospital. $\mathrm{O}$ autor coloca que as ações de demarketing também podem ser vistas como a aplicação do marketing-mix para a redução do uso de serviços e produtos, contudo, na prática, a alteração na definição do $\mathrm{P}$ de produto deve ser vista com cautela pelo fato de que pode afetar a imagem e qualquer outro fator de sucesso da empresa, pois o produto em si representa a qualidade e os benefícios oferecidos aos clientes.

As recomendações para os outros 3 Ps são, de acordo com MacStravic: (a) Preço - tornar custoso ao cliente que não requer urgência comparecer a uma emergência, tais como, o aumento dos serviços de emergência, a cobrança de taxas de estacionamento e a exigência de pagamento adiantado por alguns ou todos os serviços, inclusive, serviços que não estejam cobertos pelos seguros-saúde; (b) Promoção desencorajar o serviço para uns e encorajá-lo para outros, oferecendo uma triagem com a intenção de levar o paciente a se tratar sozinho ou a dirigir-se a clínicas de cuidados urgentes; (c) Praça - oferecer melhores alternativas aos pacientes pode ser a melhor prática para o demarketing.

Alguns hospitais americanos já estão desenvolvendo espaços próprios ou em parceria para o processo de triagem dos pacientes que merecem atendimento de urgência. Os pacientes de não emergência podem, então, ser orientados a buscar os centros de cuidados urgentes. Ao mesmo tempo, é interessante perceber que tal procedimento gera oportunidades de novos negócios. As triagens em locais como shoppings, grandes lojas e local de trabalho podem ser interessantes para pacientes e centros médicos no sentido de ampliar suas ofertas de serviços, não só de cuidados com saúde ocupacional, mas também com rotinas de cuidados primários (MACSTRAVIC, 2008).

Gristein e Nisan (2009) desenvolveram estudo de demarketing junto à população de Israel dentro do programa de redução do consumo de água, desenvolvida pelo governo, durante o período de 1999 a 2001, quando o país passou por uma estiagem. A problemática da falta de água, além de esbarrar sobre o tema da conscientização sobre a preservação dos recursos do meio ambiente, toca em questões étnicas que afetaram essa sociedade em funções dos conflitos marcados na região. 
O estudo verificou que: (a) o engajamento das minorias sociais foram menos positivas à campanha de demarketing, elas reagem de forma diferente, confirmando a hipótese de que os valores da minoria sobrepõem aos valores da sociedade; (b) o nível maior de escolaridade responde melhor ao programa de incentivo à redução de consumo de água; (c) o envolvimento das pessoas com o espírito de nacionalidade e seus valores é um importante fator para explicar seu engajamento.

Com base no comportamento distinto de aceitação quanto ao programa de demarketing entre as minorias sociais, os autores recomendam que os profissionais de marketing, ao perceberem que a referência do grupo não é o país, devem reformatar as campanhas de demarketing, desenvolvendo um discurso mais próximo do benefício do grupo do que do país em que vivem (GRISTEIN; NISAN, 2009).

Já Gerstner, Hess e Chu (1993) apresentam o demarketing como uma estratégia de diferenciação em casos que aperfeiçoar o produto não é mais eficaz. Consideram uma ideia original esse tipo de estratégia, pois ainda não havia sido abordado na literatura e seu benefício seria evitar uma guerra de preços no mercado. A ideia desses autores está centrada no raciocínio de que a inclusão de alguma característica indesejada na oferta da empresa possa desenvolver uma rejeição por parte do cliente cativo do concorrente direto. Isso faria com que a empresa criasse uma barreira na compra de seu produto, evitaria que a firma concorrente perdesse seus clientes cativos e levaria ao desinteresse por uma guerra de preços. Desta forma, a firma que promove a ação de demarketing pode aumentar o preço de seus produtos junto aos seus clientes, o que faria com que todas as empresas alcançassem um equilíbrio e obtivessem preços acima de seus custos.

Gerstner, Hess e Chu (1993) desenvolveram, por meio de uma modelagem econômica, o modo pelo qual uma empresa entrante de baixo preço, adotando uma estratégia em demarketing, pode se beneficiar frente a sua concorrência. Sob esse modelo concluíram que: (a) ações em demarketing podem fazer com que uma empresa entrante possa deter uma empresa já instalada (incumbent), instigando o concorrente para o lucro, evitando uma guerra de preços, e atingindo ambas as receitas positivas; (b) a competitividade de preço é menos intensa e os lucros são mais altos para ambas a empresa, quando a diversidade de características indesejáveis, inserida nas ofertas das empresas para os clientes, são mais amplas; e (c) o demarketing é menos lucrativo para os novos entrantes e mais para as empresas já instaladas quando, em média, o não interesse pelas características incluídas na oferta é grande. Assim, os pesquisadores puderam mostrar que, com ações em demarketing como estratégia mercadológica, é possível criar ineficiências econômicas 
no mercado, gerando um "bem-estar" na sociedade, fruto da redução da rivalidade entre as empresas.

Gerstner, Hess e Chu (1993) reforçam a recomendação de Kotler e Levy, que deram início a esse campo de conhecimento, reconhecendo a importância de se pesquisar mais sobre o assunto; entretanto, mencionam que, na prática, poucos estudos se detiveram sobre o tema, mostrando a necessidade de criar um corpo teórico mais consolidado na área. Por exemplo, Gautier (2001) apresenta dois termos sinônimos ao demarketing, a expressão d-marketing, sem a vogal "e", e a palavra deselection, que remete a teoria da seleção de Darwin, mais utilizada no Reino Unido. Percebe-se que a caracterização que Gautier (2001) adota sobre o cliente indesejado é focada principalmente no indivíduo não rentável financeiramente para a empresa, enquanto que Kotler e Levy (1971) não discutiram a respeito do cliente alvo do demarketing, pois se preocuparam em discutir o seu emprego e as estratégias a serem adotadas, contudo nota-se, ainda assim, uma conotação semelhante a de clientes indesejados.

Existem trabalhos que, mesmo não sendo caracterizados como demarketing, podem ser vistos como pertencentes a esse tema, segundo Gerstner, Hess e Chu (1993): (a) demarketing através de discriminação de preço - clientes podem ser desestimulados a comprar em determinados horários, quando a oferta com preço mais baixo é fora do horário de grande movimentação; (b) demarketing através de ações por isca/substituição - clientes podem ser motivados a adquirir certos produtos com maiores margens, buscando fisgar a sua atenção ou, então, desprestigiando os produtos eles pretendiam inicialmente; (c) demarketing por falta de estoque e rain checks - a falta de produtos pode fazer com que os clientes visitem a loja com mais frequência na busca por produtos específicos e acabem comprando artigos complementares e, em caso de solicitação de pedido por produto em falta, a lista de espera demostra que esses clientes estariam dispostos a pagar mais pelo produto; e (d) demarketing por custos de multidão - empresas podem aceitar restringir seus clientes, reconhecendo que alguns clientes estão dispostos a pagar preços maiores para evitar a multidão.

No anexo um, são apresentadas práticas e considerações sobre o demarketing que despertam para as nuances sobre esse tema e podem ser, inclusive, vistas como sugestões para outros estudos. 


\section{Metodologia}

Para esse estudo, foi utilizada uma abordagem exploratória, quanto a metodologia, que teve como objetivo levantar as percepções que funcionários da "linha de frente" tinham sobre os clientes, especificamente os clientes indesejados. Inicialmente, questionou-se os conhecimentos que possuíam sobre demarketing, e, em seguida, buscou-se registrar os problemas e as situações inoportunas criadas pelos clientes indesejados. O estudo, em sua análise, baseou-se, em parte, nos procedimentos apresentados na análise indutiva, de Thomas (2006). Identificaram-se, assim, as categorias de clientes indesejados que emergiram do discurso dos respondentes. E, com base nas categorias identificadas, apresentou-se um conjunto de recomendações.

Foi realizada uma pesquisa qualitativa por meio de entrevistas com profissionais atuantes em pequenas empresas dos setores de academias de ginástica, bares, pet shops e salões de beleza, localizados na zona sul da cidade do Rio de Janeiro. As entrevistas ocorreram junto a profissionais que trabalhavam recepcionando os clientes, independente de seus cargos, entre os meses de abril e maio de 2009 (ainda que os dados apresentem uma distância temporal entre a data de coleta e a de leitura do trabalho, considera-se este estudo válido, porque os comportamentos relacionais de clientes estão enraizados, em grande parte, em características culturais, que não mudam em um curto prazo de tempo).

Pelo menos em três empresas do mesmo ramo de negócio foram coletados os dados (em academias e bares foram realizadas vinte entrevistas; em pet shops, dezoito entrevistas; e em Salões de Beleza, três entrevistas) e, em cada estabelecimento, uma única entrevista foi realizada. A escolha dos ramos de atividade das empresas envolvidas foi por conveniência, se deu em razão da acessibilidade aos funcionários e da quantidade de empresas desses setores encontrados na região estudada.

Em razão do método de pesquisa adotado, os resultados e as conclusões devem ser considerados com cautela, pois não permitem generalizações para as empresas dos ramos estudados e, muito menos, para o universo das empresas de pequeno porte. O trabalho se baseia nos respondentes "da linha de frente" e, dependendo da posição que o entrevistado ocupa dentro da empresa, se o mesmo é dono do negócio/gerente ou se é apenas um funcionário, o levantamento de campo apresentou variabilidade nas respostas, visto que donos e gerentes possuem uma preocupação estratégica maior que funcionários apenas atendentes ou vendedores. Ainda nessa direção, outra limitação do método pode ter afetado a qualidade das respostas entre 
os entrevistados: a desconfiança que os respondentes tiveram frente as questões. Recearam que os dados fornecidos pudessem ser repassados para a concorrência, ou que, ao responder as questões do roteiro, o funcionário poderia receber alguma advertência ou punição de alguém superior ou do dono da empresa.

\section{Apresentação dos resultados}

A ideia inicial de que poderia existir cliente indesejável foi muitas vezes rechaçada, possivelmente pela forte orientação de vendas e de receita entre os respondentes. Em uma das respostas de um entrevistado, como exemplo, teve-se: "Graças a Deus eu tenho esse problema!".

A ideia de clientes indesejáveis começou a surgir entre os respondentes a partir do momento em que o diálogo foi aprofundando-se e, assim, o sentido de cliente indesejável foi resignificado, em muitas situações, para o de cliente mal-educado. Em função da experiência no relacionamento dos respondentes com os clientes indesejáveis no seu dia a dia, foram observadas duas considerações: (a) clientes fiéis não se irritam facilmente, não causando muitos conflitos, e (b) os clientes indesejáveis são geralmente os mesmos. Entretanto, pode-se observar também que, nas empresas entrevistadas, mesmo existindo clientes mal-educados, não há interesse de perdê-los.

Quanto ao demarketing, conforme esperado, nenhum dos respondentes afirmava conhecer o termo. O problema da adequação à demanda nos negócios estudados é maior em bares e pet shops nos finais de semana. Nos salões de beleza, o excesso de demanda, em grande parte, é resolvido com a reserva antecipada de horários e datas.

Nas empresas estudadas, não se verificou mecanismos para monitorar o comportamento de seus clientes com vistas a aprofundar o conhecimento sobre eles, sejam mecanismos de um sistema informatizado ou não, elas, inclusive, não realizam pesquisas de marketing. Essas empresas também não sabem da rentabilidade de cada um dos seus clientes, das suas necessidades e das suas motivações para determinados comportamentos.

As respostas acerca dos clientes indesejados dos trabalhadores de academias de ginástica estão apresentadas no Quadro 1. 
Quadro 1 - Resultados das entrevistas com funcionários de academias de ginástica

$\checkmark$ Clientes que estão sempre reclamando dos serviços e solicitando os mesmos;

$\checkmark$ Clientes antipáticos, narcisistas, chatos e inconvenientes;

$\checkmark$ Clientes mal-educados e bagunceiros, que não arrumam colchonetes e não cedem os equipamentos para outros clientes, prejudicando os demais;

$\checkmark$ Clientes que frequentam pouco a academia e não reconhecem os benefícios dos serviços.

Fonte: elaborado pelo autor.

O Quadro 2 apresenta as respostas dos funcionários que trabalham em bares.

Quadro 2 - Resultados das entrevistas com funcionários de bares

$\checkmark$ Clientes que se aproveitam de situações incômodas no restaurante para, rapidamente, apresentar o Código de Defesa do Consumidor;

$\checkmark$ Clientes que provocam confusão e consomem menos;

$\checkmark$ Público heterogêneo que causa mais conflitos.

Fonte: elaborado pelo autor.

No Quadro 3, são apresentadas as respostas dos trabalhadores do ramo de pet shop.

Quadro 3 - Resultados das entrevistas com funcionários de pet shop

$\checkmark$ Clientes de fim de semana, que sobrecarregam a demanda nesses períodos;

$\checkmark$ Clientes que "penduram", ou seja, que pagam posteriormente, sem data prevista, atrapalhando o fluxo de caixa da empresa;

$\checkmark$ Clientes que levam animais com pulgas, contaminando o ambiente e outros animais presentes na loja;

$\checkmark$ Clientes que deixam crianças ou filhos sozinhos na loja, atrapalhando o fluxo de movimentação de outros clientes no local;

$\checkmark$ Clientes indisciplinados, que, na maioria das vezes, não cumprem os horários firmados, prejudicando operações internas;

$\checkmark$ Clientes que solicitam um segundo banho em seus animais dias depois, porque acharam que não foram bem lavados;

$\checkmark$ Clientes que solicitam medicamentos específicos, não encontrados no estabelecimento.

Fonte: elaborado pelo autor.

Teoria e Evidência Econômica - Ano 23, n. 48, p. 204-221, jan./jun. 2017 
As respostas dos funcionários do ramo de salões de beleza estão dispostas no Quadro 4.

Quadro 4 - Resultados das entrevistas com funcionários de salões de beleza

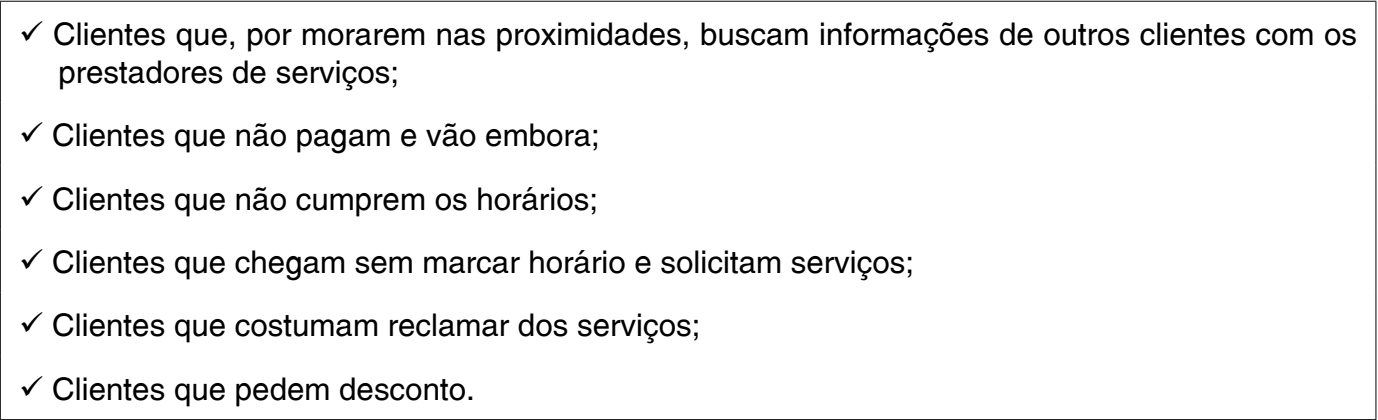

Fonte: elaborado pelo autor.

Ao observar as respostas dos funcionários dos diversos segmentos de negócios, constata-se que os clientes indesejáveis podem ser resumidos em dez categorias, segundo a metodologia de análise de Thomas (2006), não necessariamente excludentes uma da outra: (1) clientes mal-educados, (2) clientes perturbadores da ordem, (3) clientes não cumpridores de horários, (4) clientes que costumam reclamar dos serviços sem razão, (5) clientes aproveitadores de situações desconfortáveis nos estabelecimentos, (6) clientes barganhadores, (7) clientes que solicitam produtos/ serviços muito específicos, não disponíveis e sem interesse de serem ofertados pela empresa, (8) clientes que não percebem os benefícios da oferta da empresa, (9) clientes de fim de semana e (10) clientes com características muito heterogêneas.

\section{Conclusões e recomendações}

$\mathrm{Na}$ análise dos resultados, identificou-se dez categorias de clientes indesejados entre funcionários dos negócios de academias de ginástica, bares, pet shops e salões de beleza. Nas quatro últimas categorias de clientes indesejados, percebe-se que a gerência de marketing de uma empresa possuiria estratégias de como lidar com essas situações, com suporte da literatura acadêmica (GAUTIER, 2001; KOTLER; LEVY, 1971; MACSTRAVISC, 2008), por exemplo: o emprego de estratégias de promoção para as categorias sete (clientes que solicitam produtos/serviços muito específicos, não disponíveis e sem interesse de serem ofertados pela empresa) e oito (clientes que não percebem os benefícios da oferta da empresa); e uma 
comunicação mais informativa e direcionada, com estratégia de segmentação, para as categorias nove (clientes de fim de semana) e dez (clientes com características muito heterogêneas).

Nas demais categorias, de um a seis, não haveria estratégias claras de como a empresa deveria lidar nessas situações, fato compreensível já que a problemática é de cunho moral, fora do âmbito da disciplina de marketing. Elas requerem, por vezes, medidas socioeducativas. Observa-se que os principais livros de marketing adotados em disciplinas da área, não possuem capítulo específico sobre demarketing, e, portanto, muito menos quanto a questões morais, restando ao profissional interessado recorrer a fontes específicas sobre $o$ assunto.

Embora todas as outras categorias não estejam sob a responsabilidade direta das empresas, elas também devem se tornar preocupações das gerências de marketing, pois podem prejudicar a qualidade de atendimento a outros clientes e levar a empresa a um prejuízo da sua imagem, principalmente quando os funcionários não estão preparados para lidar com tais situações, gerando, inclusive, desapontamento e desmotivação da equipe.

Diante das dez categorias identificadas na pesquisa, o Quadro 5 apresenta resumidamente os clientes elencados e suas características, seguindo os procedimentos de Thomas (2006).

Quadro 5 - Resumo de categorias de Clientes e suas características em função do relacionamento e da capacidade de produção/atendimento

\begin{tabular}{|c|c|}
\hline Clientes & Características \\
\hline $\begin{array}{l}\text { (1) Clientes dignos de } \\
\text { relacionamento }\end{array}$ & $\begin{array}{l}\text { Excelentes e bons clientes, antigos ou novos, que realizam trocas justas } \\
\text { com a empresa em momentos adequados. }\end{array}$ \\
\hline $\begin{array}{l}\text { (2) Clientes } \\
\text { deselegantes }\end{array}$ & $\begin{array}{l}\text { Clientes mal-educados, não honradores de horários e pagamentos, } \\
\text { aproveitadores, esnobes, críticos sem razão etc. Especial atenção deve } \\
\text { ser dada aos que prejudicam a empresa, seja na capacidade produtiva, } \\
\text { seja na imagem da empresa junto aos clientes dignos. }\end{array}$ \\
\hline $\begin{array}{l}\text { (3) Clientes } \\
\text { problemáticos }\end{array}$ & $\begin{array}{l}\text { Clientes mais graves, que se comportam contra as leis e as regras so- } \\
\text { ciais aceitáveis. }\end{array}$ \\
\hline $\begin{array}{l}\text { (4) Clientes de } \\
\text { sobrecarga }\end{array}$ & $\begin{array}{l}\text { Clientes novos ou esporádicos, com alguma frequência de relacionamen- } \\
\text { to, que aparecem em períodos críticos, sobrecarregando a capacidade } \\
\text { produtiva, como finais de semana, determinados horários e períodos. }\end{array}$ \\
\hline (5) Clientes out & Clientes que estão fora da definição de público-alvo da empresa. \\
\hline $\begin{array}{l}\text { (6) Clientes de puro } \\
\text { demarketing }\end{array}$ & $\begin{array}{l}\text { Clientes que a empresa é incapaz de atender, seja por incapacidade } \\
\text { produtiva, seja por qualquer outra razão específica. }\end{array}$ \\
\hline
\end{tabular}

Fonte: elaborado pelo autor. 
Para colaborar nas decisões de marketing, é sugerido, no Quadro 6, recomendações de ações que podem ser executadas pelas empresas. É necessário que a empresa entenda a importância de monitorar o perfil e o comportamento de seus clientes, para que possa tomar uma decisão adequada.

Quadro 6 - Proposta de ações para gerenciar cada um dos tipos de clientes.

\begin{tabular}{|c|c|}
\hline Clientes & Ações \\
\hline $\begin{array}{l}\text { Clientes dignos de relacio- } \\
\text { namento }\end{array}$ & $\begin{array}{l}\text { Melhoria contínua no relacionamento e nas estratégias de marke- } \\
\text { ting, buscando, na medida do possível, a redução de custos. Prio- } \\
\text { rizar a oferta aos clientes dignos de relacionamento, seja através } \\
\text { de um agendamento, seja por atendimento preferencial. }\end{array}$ \\
\hline Clientes deselegantes & $\begin{array}{l}\text { Estabelecimento de um plano de comunicação efetiva e eficaz a } \\
\text { fim de modificar comportamentos indesejáveis no relacionamento, } \\
\text { buscando a migração para o segmento de clientes dignos e trei- } \\
\text { nando continuamente os funcionários para o desenvolvimento de } \\
\text { atitudes e ações adequadas no contato com esses clientes. } \\
\text { A oferta precisa, continuamente, ser valorizada entre os clientes, } \\
\text { para aprenderem a valorizar o relacionamento. }\end{array}$ \\
\hline Clientes problemáticos & $\begin{array}{l}\text { Política de exclusão dos clientes ou de busca por medidas pro- } \\
\text { tecionistas para a imagem da empresa frente a outros clientes, } \\
\text { defendendo-se de futuros problemas legais. }\end{array}$ \\
\hline Clientes de sobrecarga & $\begin{array}{l}\text { Desenvolvimento de estratégias de migração do cliente para situa- } \\
\text { ções favoráveis de prestação de serviço (por exemplo, clientes de } \\
\text { finais de semana para durante a semana) ou busca de eficiência } \\
\text { produtiva interna ou através de parcerias. } \\
\text { Procurar fidelizar este tipo de cliente, empurrando-o para períodos } \\
\text { fora de pico ou oferecendo serviços inferiores. Se a rentabilidade } \\
\text { do cliente, financeira ou não, não compensar, ele pode ser condu- } \\
\text { zido, por sugestão, para outras empresas. }\end{array}$ \\
\hline Clientes out & $\begin{array}{l}\text { Desenvolvimento da imagem do tipo de cliente desejado através } \\
\text { de uma comunicação eficaz, buscando a saída espontânea dele } \\
\text { do segmento. }\end{array}$ \\
\hline $\begin{array}{l}\text { Clientes de puro demarke- } \\
\text { ting }\end{array}$ & $\begin{array}{l}\text { Orientação do cliente para outra empresa, procurando manter a } \\
\text { imagem positiva da empresa. }\end{array}$ \\
\hline
\end{tabular}

Fonte: elaborado pelo autor.

Este estudo aponta que clientes nem sempre possuem razão na percepção das pessoas que trabalham na "linha de frente", e, por vezes, apresentam comportamentos inadequados que prejudicam a prestação dos serviços para outros clientes, impactando na motivação dos funcionários. A compreensão dessa realidade 
contribui para pensar ações que venham a garantir uma maior satisfação dos funcionários com suas atividades, ensinando-os a lidar com as dificuldades e, principalmente, mantendo o objetivo da empresa de satisfazer os clientes.

Mesmo que não fosse o objetivo deste trabalho, observa-se que é ainda forte a orientação das empresas para vendas e receitas em detrimento da satisfação com a prestação de serviço e a preocupação com a fidelidade (ou seja, em direção, muitas vezes, oposta à orientação de marketing). Em grande parte das vezes, a ideia de construção de relacionamentos de longo prazo com clientes ainda não é um valor presente dentro das empresas, mostrando a falta de preparo dos gestores de negócios.

Novos estudos podem ser realizados em outros segmentos de negócios, além de outros trabalhos que tragam novas ideias para as estratégias de demarketing, ampliando discussões sobre o tema e, sobretudo, quanto ao gerenciamento de questões delicadas, de natureza moral, com vistas a integrar às atividades normais de marketing, praticadas atualmente pelas empresas de pequeno porte. 


\title{
A study on unwanted customers in small businesses
}

\begin{abstract}
Unwanted clients are part of the routine of many companies, and unfortunately affect not only the existing processes of firms, but also undermine the motivation of employees and sometimes generate nuisances to other customers. This exploratory study investigated the types of unwanted customers in small business in gyms, bars, pet-shop's and salons with the service employees and sales that were in the "front line" with customers. Understanding this reality contributes to rethink in some actions that will provide greater satisfaction of employees, seeking to train them in how to deal with such difficulties.
\end{abstract}

Keywords: Demarketing. Small Businesses. Unwanted Clients.

\section{Un estudio sobre los clientes no deseados en pequeñas empresas}

\section{Resumen}

Clientes no deseados son parte de la rutina de muchas empresas y lamentablemente afectan no sólo los procesos existentes de las empresas, pero también minan la motivación de los empleados y a veces generan molestias a otros clientes. Este estudio exploratorio había investigado los tipos de clientes no deseados en pequeño negocio en gimnasios, bares, pet shop y salones con los empleados de servicio y ventas que estaban en la "línea de frente" con los clientes. La comprensión de esta realidad contribuye a replantear algunas acciones que proporcionen una mayor satisfacción de los empleados, buscando para entrenarlos sobre cómo hacer frente a esas dificultades.

Palabras clave: Clientes no Deseados. Demarketing. Pequeñas empresas. 


\section{Referências}

DAMATTA, R. Carnavais, malandros e heróis, para uma sociologia do dilema brasileiro. Rio de Janeiro: Rocco, 1997.

GAUTIER, A. Unwanted customers. NZ Marketing Magazine, Auckland - Nova Zelândia, v. 20, e. 9. p. 11-15, out. 2001 .

GERSTNER, E.; HESS, J.; CHU, W. Demarketing as a differentiation strategy. Marketing Letters, [S.l.], v. 4, n. 1, p. 49-57, 1993.

GORDON, I. Relationship demarketing: managing wasteful or worthless customer relationships. Ivey Business Journal, Ontario - Canadá, v. 70, n. 4, p. 1-4, mar./abr. 2006.

GRISTEIN, A.; NISAN, U. Demarketing, minorities and national attachment. Journal of Marketing, Chicago - Estados Unidos da América, v. 73, p. 105-122, mar. 2009.

KOTLER, P.; LEVY, S. Demarketing, yes demarketing. Harvard Business Review, Boston - Estados Unidos da América, v. 49, n. 6, p. 74-80, nov./dez. 1970.

MEDWAY, D.; WARNABY, G. Alternative perspective on marketing and the place brand. European Journal of Marketing, Bingley - Reino Unido, v. 42, n. 5/6, p. 641-653, 2008.

MACSTRAVIC, S. The last word. Marketing Health Services, Chicago - Estados Unidos da América, p. 36, inverno 2008.

SULLIVAN, E. A. Just say no. Marketing News, Chicago - Estados Unidos da América, v. 42, p. 16-17, abr. 2008.

THOMAS, D. R. A general inductive approach for analyzing qualitative evaluation data. American Journal of Evaluation, [S.l.], v. 27, n. 2, p. 237-246, jun. 2006. 


\section{Anexo 1 - Práticas e considerações sobre demarketing}

Prioridade ao segmento empresarial: as empresas dentro do mercado B2B (business-to-business) tendem, naturalmente, a excluir pequenos clientes por negligência, a partir do momento em que focam as grandes contas. Dentro do B2C, diferentemente do ambiente de negócio anterior, a prática entre os bancos e seguradoras é algo que ocorre há muito tempo através de preços mais altos e concessão de descontos.

Critérios não padronizados sobre cliente rentável (desejado): a definição de um cliente rentável pode variar de acordo com cada profissional. Enquanto uns estão conceituando através do volume de negócios, outros podem caracterizá-los como àqueles que possuem um comportamento desejável como, por exemplo: são de fácil trato, são razoáveis, compreendem a oferta da empresa e estão dispostos a pagar por ela.

Clientes globais, filiais não rentáveis localmente: empresas subsidiárias locais podem ser forçadas a ficar com os clientes não rentáveis a partir do momento em que a matriz estabelece um relacionamento com o cliente a nível global.

Custos dos clientes indesejados: apresentam desvantagens para as empresas pelos seguintes aspectos observados $\square$ (a) apresentam pouco potencial de aprendizagem para a empresa no sentido de desenvolver inovações, (b) prejudica o relacionamento com clientes rentáveis a partir do momento em que precisam se preocupar com o cliente não rentável e (c) geram sentimentos de aflição entre as partes.

Valor estratégico do Cliente: as empresas podem realizar ações demarketing não apenas em função da não rentabilidade do cliente, mas sob o ponto de vista estratégico da organização, a firma decide em não querer crescer em termos de clientes de determinado perfil. Mesmo que os clientes reconhecessem a competência da firma, esta última pode não desejar alguns clientes, pois a oferta desejada não é uma competência que a empresa queira desenvolver.

Ampliação da frequência e práticas em demarketing: ocorre naturalmente junto às empresas, sendo descritas em manuais das organizações. Por exemplo, na Nova Zelândia, a empresa Greenacre inicialmente buscou obter um aumento nas vendas, ou up-skill, junto aos seus clientes, caso contrário, os franqueados poderiam solicitar ao gerente regional aumento de preço. Caso o cliente não concordasse em pagar, a relação entre as partes terminaria. Bancos e seguradoras já praticam, há bastante tempo, políticas de redução de bônus e de aumento de prêmios para desencorajar clientes. Em pesquisa feita em 1999, no reino Unido, constatou-se que mais da metade dos bancos utiliza-se de estratégias em demarketing.

Relacionamento com clientes indesejados: pelo menos na Nova Zelândia ocorre, entre os profissionais de marketing, uma valorização do volume de clientes, mesmo que, racionalmente, eles saibam que deveriam especializar-se numa estratégia de nicho. As empresas que preferem investir nos clientes indesejados, não rentáveis, fazem-no através de uma abordagem de vendas cruzadas ou de uma ampliação de vendas. Outras empresas tentam, através do aumento nos preços, a retirada de parte da oferta. 
Relações sociais dos clientes indesejados: além da tentativa de estabelecer uma resposta mais positiva por parte dos clientes indesejados, as empresas preocupam-se com os benefícios que eles produzem em termos de melhora no fluxo de caixa e de contribuição dos custos fixos das empresas. Outro ponto importante a ser observado relaciona-se ao rateio dos custos juntos aos clientes. Se o procedimento for através de uma média a ser imputada para cada cliente, pode acarretar em uma falsa percepção de falta de rentabilidade do cliente indesejado, quando, na verdade, pode não ser.

Relações sociais dos clientes indesejados: de acordo com Bob Chatham, da empresa de pesquisa Forrester, é melhor assumir o cliente indesejado como rentável no caso de dúvidas. Para esse profissional, o valor do cliente pode ser visto de outras formas como, por exemplo, pode ser um "evangelizador" da empresa, recomendando produtos e serviços para outros clientes. Nesse caso, alerta-se que é importante compreender os relacionamentos e as redes que os clientes possuem, mesmo que sendo quase impossível, pois, ignorar esse fato, pode ser um risco grande para as empresas.

Valor do cliente indesejado ao longo do tempo: uma tendência com relação ao exame dos clientes indesejados é avaliar o valor do cliente no tempo de vida do relacionamento. Clientes indesejados, sob o ponto de vista da rentabilidade, podem ser, em um primeiro momento, ruins para as empresas, como, por exemplo, os clientes universitários, que ficariam abaixo da média de ganhos, porém, com o tempo, podem tornar-se excelentes clientes.

Estratégias erradas em marketing: a ideia de que um cliente novo custa muito mais para uma empresa do que a manutenção de um cliente já existente, faz com que muitos profissionais de marketing tendam a acreditar que conservá-los ou desenvolvê-los é a estratégia mais adequada para as organizações. Observar as possíveis causas para a existência do cliente insatisfeito pode ser o primeiro passo para corrigir a situação. Isto se torna mais importante à medida que aumenta a base de clientes indesejados, pois indica a existência de um problema interno na empresa, seja por oferecer um preço abaixo do seu valor, seja por oferecer muito valor frente aos seus custos. Algumas ações simples podem fazer com que clientes indesejados tornem-se rentáveis, por exemplo, desestimulando a utilização de call centers, encaminhando mensagens de Frequently Asked Questions (FAQ) e orientando-se através de comunicação por e-mails, em vez de correspondências pelo correios.

Atitude fraca do cliente sobre a empresa: outro ponto importante na estratégia errada de marketing com o cliente não rentável é a falta de desenvolvimento de uma atitude positiva junto aos clientes. É preciso uma mudança de atitude dos clientes com relação ao aprendizado de percepção de valor da oferta da empresa. À medida que se amplia essa consciência, mais fácil é para a empresa levar o cliente indesejado para a rentabilidade. Um exemplo disso é sugerido pelo executivo da KPMG junto aos seus clientes, que apresentam o certificado da empresa na obtenção de empréstimos junto aos bancos.

Fonte: resumido de Gautier (2001).

Teoria e Evidência Econômica - Ano 23, n. 48, p. 204-221, jan./jun. 2017 